\title{
Service robots in the hospitality industry: The case of Henn-na hotel, Japan
}

\author{
João Reis $^{\text {a,b, }}{ }^{*}$, Nuno Melão ${ }^{c}$, Juliana Salvadorinho ${ }^{a}$, Bárbara Soares ${ }^{a}$, Ana Rosete ${ }^{a}$ \\ ${ }^{a}$ Department of Economics, Management, Industrial Engineering and Tourism, GOVCOPP, Aveiro University, Campus Universitário de Santiago, 3810-193, Aveiro, \\ Portugal \\ ${ }^{\mathrm{b}}$ Industrial Engineering and Management, Lusofona University and Dreams Research Unit, Campo Grande, 1749-024, Lisbon, Portugal \\ ${ }^{\mathrm{c}}$ CISeD - Research Centre in Digital Services, Avenida Coronel José Maria Vale de Andrade, 3504-510, Polytechnic Institute of Viseu, Viseu, Portugal
}

\section{A R T I C L E I N F O}

\section{Keywords:}

Artificial intelligence

Empathetic intelligence

Hospitality industry

Service industry

Service robots

\begin{abstract}
A B S T R A C T
Services are changing at an impressive pace boosted by the technological advances felt in Robotics, Big Data, and Artificial Intelligence (AI) that have uncovered new research opportunities. Our objective is to contribute to the literature by exploring the pros and cons of the use of service robots in the hospitality industry and to practice, by presenting the architectural and technological characteristics of a fully automated plant based on a relevant case. To achieve such goal, this article uses a systematic literature review to assess the state-of-the-art, characterize the unit of analysis, and find new avenues for further research. The results indicate that, in high customer contact settings, service robots tend to outperform humans when performing standardized tasks, because of their mechanical and analytical nature. Evidence also shows that, in some cases, service robots have not yet achieved the desired technological maturity to proficiently replace humans. In other words, the technology is not quite there yet, but this does not contradict the fact that new robot technologies, enabled by AI, will be able to replace the employees' empathetic intelligence. In practical terms, organizations are facing challenges where they have to decide whether service robots are capable of completely replacing human labor or if they should rather invest in balanced options, such as human-robot systems, that seem to be a much more rational choice today.
\end{abstract}

\section{Introduction}

When radio arrived, many thought it would mean the end of books; when television came, some believed it would be the downfall of radio; now robots have arrived and they are here to stay [1] and one may well wonder if they will completely replace the human work [2]. It is a well-known fact that robots have been studied for a while now [3]. Three decades ago, Engelhardt [4] argued that service robots encompassed a wide spectrum of technological fields and held the potential for combining or even for surpassing industrial use. Those were perhaps very optimistic words for the time, but in fact, over time, we have witnessed the inclusion of service robots in several daily activities [5] such as healthcare [6-8], education [9] or mobility [10]. Moreover, consumer acceptance has made service robots' technologies one of the most recent entries in the field of hospitality [11]. Thus, the centrality of service robots in shaping contemporary hospitality has been pivotal [12] to the management literature.

Artificial intelligence (AI) has long been improving robots to enable them to provide efficient human services [4,12], and is now getting significant attention from service companies operating in tourism and hospitality fields [13].

On the other hand, recent research conducted in the hospitality industry has shown that although AI plays an important role in improving business operations, it is human intelligence, with all the emotional abilities it encompasses, that plays a dominant role in managing employees and customers [14]. Other attempts have been made in relation to the anthropomorphic qualities of service robots [15], giving them a more human-like appearance, as well as establishing measurement tools for human-robot interactions (HRI) [16].

Fully automated hotels are still a niche market that may not represent the sector in the near future and, as such, it is difficult to transfer learning to another tourist activity, since they are built for a specific purpose. However, there have been several call for papers from top-tier Journals, such as the "Artificial Intelligence in Hospitality and Tourism" [17] from the International Journal of Contemporary Hospitality Management or the call "Digitalization and Sustainability in the Tourism and

\footnotetext{
* Corresponding author. Department of Economics, Management, Industrial Engineering and Tourism, GOVCOPP, Aveiro University, Campus Universitário de Santiago, 3810-193, Aveiro, Portugal.

E-mail addresses: reis.joao@ua.pt (J. Reis),nmelao@estgv.ipv.pt (N. Melão), juliana.salvadorinho@ua.pt (J. Salvadorinho), barbaramsoares@ua.pt (B. Soares), anarosete@ua.pt (A. Rosete).
} 
Hospitality Sectors" from the Journal of Sustainable Tourism [18], which leads us to believe that the range of research is broader than that of hospitality, being also relevant, for example, in the areas of tourism and leisure.

Despite the growing interest of academics in the service robot arena, little academic attention has yet been devoted to this topic, particularly in the field of frontline hospitality services. While professionals are at the forefront of many current developments, academics are increasingly being challenged to keep up with the pace [19]. It also seems that there is a greater need for quantitative and empirical studies [20] than for theoretical debates. Theoretical studies, however, can be an important support to new research, as in the case of, for instance: 1) theories such as those proposed by Solomon et al. [21] that have contributed to the assessment of service robots; or 2) recommendations, such as those found in Ivanov and Webster's work [22] that were particularly useful to offer guidelines for further research.

Without relying too much on conceptual analysis, our scientific research will be based on two theoretical articles that have been recently published: 1) an article entitled "Brave new world: service robots in the frontline", by Wirtz et al. [23]. This article allowed us to study frontline service robots in specific hospitality contexts, and, more specifically, to analyze their performance in the Henn-na hotel; 2) a second article entitled "Artificial intelligence in service", by Huang and Rust [24]. This last article helped us understand the relation between $\mathrm{AI}$ and service robots' technologies and how this association can progress to replace human labor, according to the specifics of each hospitality task.

Bazzano and Lamberti [5] conducted a research that is quite similar to ours and that focused on solutions for human-robot interfaces for interactive receptionist systems. Kervenoael et al. [20] conceptualized and empirically tested visitors' intention to use social robots in hospitality services, and Choi et al. [25] examined the dimensions of service quality in the light of the influence of human-robot interaction from the perspective of hoteliers and hotel guests.

The gap we identified has to do with a wide variety of studies that explore the effects of the relationship between service robots with customers and employees in the context of hospitality industry. However, they neglect or at least do not devote comprehensive research efforts to the study of fully automated hotels. Therefore, our research is different to the extent that it analyzes a real-life scenario of a hotel that uses service robots without any human participation through the entire service process. The unit of analysis allowed us to analyze the positive and negative outcomes of dealing with service robots in frontline services, and to propose avenues for further research based on AI solutions.

We structured this article into six sections. We start by presenting an overview of the topic, which includes the main theories that back up our research, similar studies, research gaps and research goals. Then, we discuss the most relevant terms of service robots characteristics of fully automated hotels, followed by a section that explains how the methodological process was carried out. In addition, we discuss the outcomes of the research and their implications for the hospitality sector; in other words, we will present and discuss the pros and cons of having service robots at the frontline of the Henn-na hotel and the use of AI as a complement to service operations. Finally, we put forward implications for theory and practice, research limitations, as well as suggestions for further research.

\section{Conceptual background}

In the remainder of this section, we will first define what is meant by service robots, with particular focus on the situation in the Henn-na hotel, and discuss the concept of AI. Next, we will present the main service robots dimensions proposed by Wirtz et al. [23] that will be useful to compare the characteristics and capabilities of service robots with those of frontline employees, and provide a deep understanding of the types of tasks that can be predominantly achieved by robots and by humans. We will also describe Huang and Rust's [24,26,27] frameworks that put forward different degrees of implementation of AI technologies to replace human activities.

\subsection{Defining service robots}

Service robots are developing new ways of interacting with customers and providing new service experiences in the hotel sector [28]. As recently advanced by Belanche et al. [3, p. 205], the definition of the term "robot" is a critical and necessary effort to help establish the limits of the field and define which approaches are most relevant. The author states that robot "is a standardized, general term, though several overlapping concepts also can describe robotic entities" [3, p. 205].

Service robots are defined as "system-based autonomous and adaptable interfaces that interact, communicate and deliver service to an organization's customers" [23, p. 909]. However, service robots have multiple definitions in the literature [30], like Bowen and Morosan's [31] who include the intelligence concept in their definition and state that robots are "physically embodied artificially intelligent agents that can take actions that have effects on the physical world", or Kachouie's et al. [32] that, albeit not giving a formal definition, argues that service robots are mainly used to support basic tasks of independent living, such as mobility and navigation.

If we focus on the physical forms, service robots can present several categories, depending on their anthropomorphism level, i.e. their human-like attributes. The most commons are [33,34]: Mechanoids, which are robots that do not resemble human beings, and whose physical appearance is similar to a machine; Humanoid robots that, although perceivable as robots, have human-like appearance features. In this regard, Belanche et al. [29] refer that the Spanish Association of Hotel Managers predicts that $96 \%$ of hotel reception desk workers will be replaced by these robots by 2029 , and $42 \%$ of food and drinks delivery in hotels will be performed by such robots in 2023; Androids are robots whose appearance, behavior and attitude are the closest to the real human being.

Robots can also assume other forms besides the anthropomorphic ones [35,36,36]: Zoomorphic (a robot that takes the form of an animal), Caricatured (a robot that takes the form of a representational object), and Functional (a robot that takes the form of a functional object).

\subsection{Service robots and AI supporting theories}

Based on the technology acceptance model [38], Wirtz et al. [23] generically define three dimensions with regard to customer acceptance of frontline service robots: the functional dimension is linked to the service robots' perceived functionality, such as perceived ease-of-use, perceived usefulness and their congruency with subjective social norms; the socio-emotional dimension is affected by the perception of (a) the humanness that robots transmit to others (human-like robots) which is reflected in the robots' level of anthropomorphism or in their nonverbal social signs [39], (b) social interactivity, i.e., the robots' human-like behavior that will improve human acceptance [40], (c) social presence, which refers to human-robot interaction (HRI) where robots are perceived as social elements during the service encounter [41]; finally, the relational dimension is associated to the feeling of confidence, comfort and trust that robots convey to human beings [42, 43].

Wirtz et al. [23] also characterizes service robots by type of service in terms of task-type and recipient of service; social-emotional and cognitive complexity; and physical task functionality and service volume. The type of task and recipient of service differs based on whether a service is targeted at people or their belongings or whether these services are tangible/intangible [19]. The socio-emotional and cognitive complexity was studied by Huang and Rust [24] who defined four levels of intelligence that will be defined below. Regarding the functionality of the physical task and service volume, it is foreseeable that, in the near future, employees will work side-by-side with robots, with the latter 
having to deal with heavy workloads or dangerous tasks, while humans will be responsible for carrying out tasks of added value.

Finally, Wirtz et al. [23] investigates the impact of service robots at three levels (Fig. 1): the micro level is concerned with the customer's experience of certain issues like privacy $[44,45]$, security [46], dehumanization, depersonalization [19,23], and social deprivation [23]. It is also related to the kind of training that employees need to be able to deliver consistent services; the meso level focuses on the markets for a specific service and on market prices fluctuations due to the falling cost of using robots and their viability in the services industry's processes [28]; the macro level is related to social and employment issues [47], as well as to inequalities within and between societies [23]. All of these levels will be part of our analysis. While Wirtz et al. [23] have brilliantly focused their research on the attributes, features and capabilities of frontline service robots, Huang and Rust [27] have tried to develop strategies and theories for the use of $\mathrm{AI}$ in services, often provided in collaboration with service robots, which for us has proved to be a great research opportunity.

A first conceptual framework offered by Huang and Rust's work pointed to technology as a primary force in the expansion of the service economy [27]. Thus, they developed a technological innovation framework which focused on automated technology, thinking technology, and feeling technology [26]. Later, the same authors refined the aforementioned structure, now based on four AIs (mechanical, analytical, intuitive and empathetic) to predict the extent to which AI will replace human work [24].

Finally, Huang, Rust and Maksimovic [48] simplified the four AIs into three and established guidelines on how to use the different AI to engage customers based on considerations about the nature of the service task, service offering, service strategy and service process; and, thus, AI develops from mechanics, thinking and feeling (Fig. 2).

Mechanical services should be performed mostly by mechanical AI and used for standard and routine tasks. Thinking $A I$ is expected to be adopted for personalized interaction and when the service is rich in data. Finally, Feeling AI should be used for relational services or when a high degree of social and emotional contact with customers is at stake. In this context, some steps have already been taken to develop social emotions. For instance, the International Society of Research on Emotion [49] and the Consortium of European Research on Emotion [50] have made significant efforts at a multidisciplinary level on a global and European scale. These groups were founded to promote the study of emotion theory and stimulate scientific research in an area where there has been a deep disregard for emotions [51]. In this regard, adding

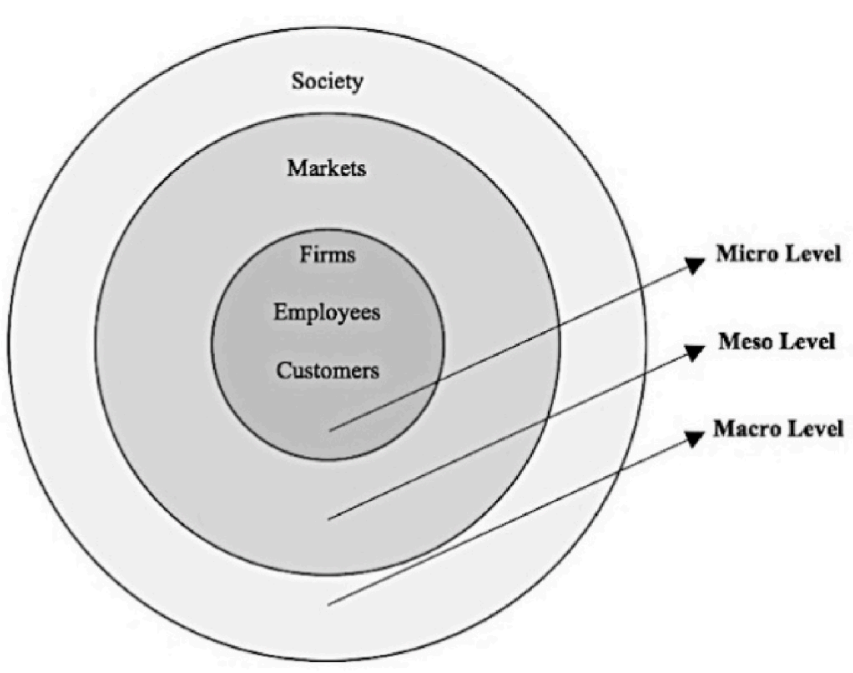

Fig. 1. Impact of service robots on key stakeholders (adapted from Wirtz et al. [23]). socio-emotional capabilities to robots is one of the most profound advances in $\mathrm{AI}$ and a development whose contribution to the service sector has been extremely valuable in recent years [30]. For these reasons, social robots have been increasingly studied as they are a subset of service robots and have the additional ability to interact and communicate with humans following rules and behavioral norms [52].

In short, what we are trying to show is that there is a broad consensus in the literature that the first levels of AI, when combined with service robots, are meant to perform any sort of mechanical tasks; on the other hand, there is still a considerable debate about the efficient use of robots and their combination with AI when it comes to provide emotional and social services. When compared to the human being, service robots have somewhat fell short to meet the expectations, as we will see later in the discussion section.

\section{Henn-na hotel characterization}

After defining the most relevant terms and having discussed the main theories, we present the section 3, which forms the empirical context of the research, while it characterizes the Henn-na hotel before proceeding to the analysis of our research unit. This section is suited to practitioners or academics who want to know more about the architectural and technological characteristics of fully a automated plant based on the Henn-na case.

\subsection{Service robots and AI features in innovative hotels: the case of Henn- na hotel}

A notable example of the use of service robots in the frontline in the hospitality industry is the Henn-na Hotel, in Japan. The Henn-na hotel opened in mid-2015 and is said to be the first fully automated robotstaffed hotel, where customers have no contact with a human employee throughout the whole service experience [1,53].

According to Osawa et al. [54] the Henn-na hotel is divided into five areas (Fig. 3). In building $\mathrm{A}$, in the reception area (c), we can find receptionist robots, i.e. a female android and a zoomorphic robot (dinosaur) that serve guests (Fig. 4). These robots perform actions by reacting as the guests push a certain button, so AI technologies, such as speech recognition, are not used at all.

A preliminary analysis shows that service robot's visual appearance seems to be a major factor influencing users' perceptions. In general, anthropomorphic robots are preferred in social settings [56]. Thus, humans treat mechanoids less emphatically than they do with humanoids [57]. However, Li et al. [58], when comparing anthropomorphic and zoomorphic robots, did not find any evident preferences. In contrast, humans have shown a less positive response to anthropomorphic agents working as frontline employees than they do to humans [59, 60]. One of our goals will be to analyze more closely the implications that frontline robots had in service delivery at the Henn-na hotel.

At the entrance, area (b), a stationary robot arm (mechanical AI) works to carry and store the luggage (a), and there are vending machines in area (e) to sell some amenities [54,61]. Buildings A to C, area (f), are the places for desktop and cleaning robots (d). The porter robot (f) moves from the entrance building through the whole building A and its function is to carry the guests' bags to their rooms. Outside the rooms, area $(\mathrm{g})$, the access is granted using facial recognition and the registration is carried out at the reception hall (b) [54]. In-room robot companion Tulie (e) operates on voice command and reacts to the guests' requests through $\mathrm{AI}$ technology, i.e. speech recognition, to control the television, lights, temperature, etc. [62].

In light of the above, it is quite evident that there are service robots, like Tulie (Fig. 4), that use complementary technologies, such as AI. On the other hand, some robots respond only to customer stimuli with standardized responses, and are, therefore, more limited. It is reasonable to assume that not all the frontline service robots are equipped with the latest technologies, since creating a hotel requires a large investment 


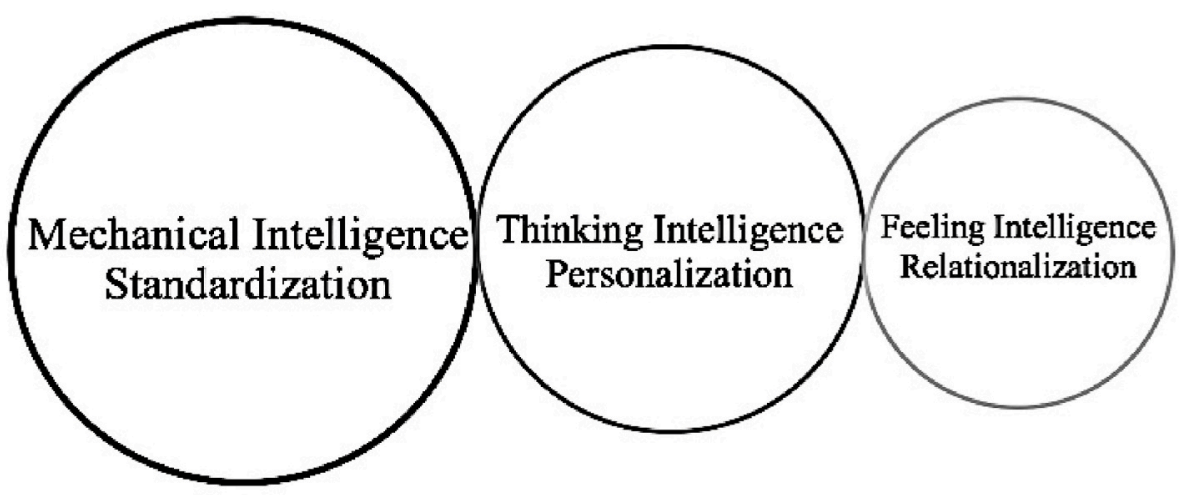

Fig. 2. Artificial intelligence engagement in services (adapted from Huang and Rust [27]).

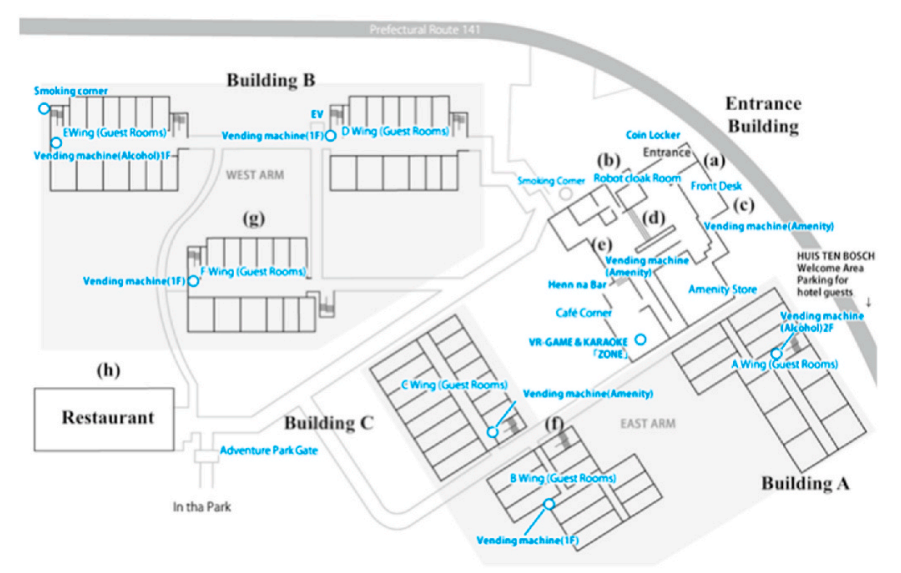

Fig. 3. Henn-na Hotel, 2020 Map (adapted from Osawa et al. [54], Henn-na hotel website [55]).

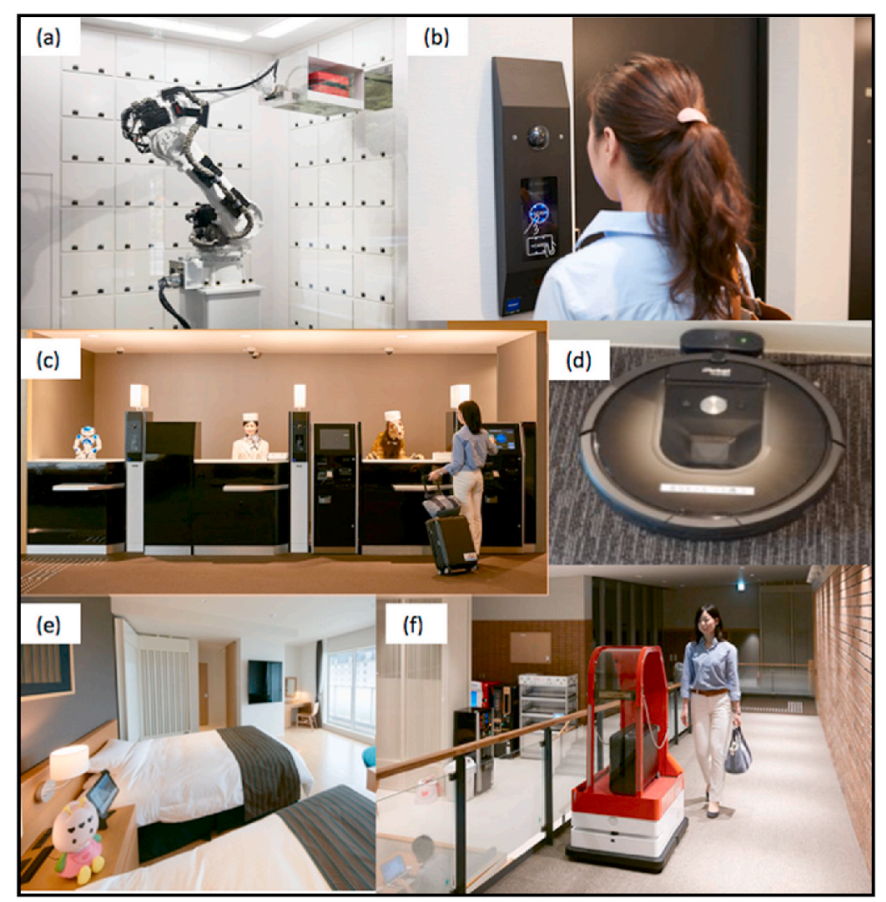

Fig. 4. Frontline service robots and automated machines: a robot cloakroom; b facial recognition; c front desk robot; d cleaning robot Roomba; e Robot agent Tulie; f Porter robot (adapted from Osawa et al. [54], Uniq Hotels [61]). that goes beyond technology. With this factor in mind, we will present some considerations on AI, and the extent to which this complementary technology can benefit hospitality service robots.

It is worth noticing that Computer Science is AI classical and natural field and that only lately has it evolved to Business Economics and, particularly, to the hospitality industry, so there is still a lot to learn about its use in the latter context [19,63,64]. The latest advances in AI have spurred the development of complex service robots that are increasingly going from being standalone machines to becoming network entities that collectively generate intelligence [11,19]. A good example are room service robots which greet customers by their name and ask them if they wish to add a service preference to their profile.

In addition, some of the most famed AI advances in the hospitality industry are (Fig. 5): (a) the Hilton hotels' humanoid concierge "Connie" ${ }^{1}$ that was developed in collaboration with IBM [13]. While powered by AI, "Connie" is capable of providing on-the-spot answers to questions, to suggest visit-worthy attractions, and to self-learn for improved performance $[1,61,69]$. Connie's brain is based on IBM's flagship AI platform Watson, and is supposed to work side-by-side with Hiltons' human frontline staff [70]. IBM Watson represents a first step into cognitive systems and builds on the combination of several AI technologies, such as natural language processing, deep learning and machine learning, by helping to improve learning based on outcomes from each iteration and

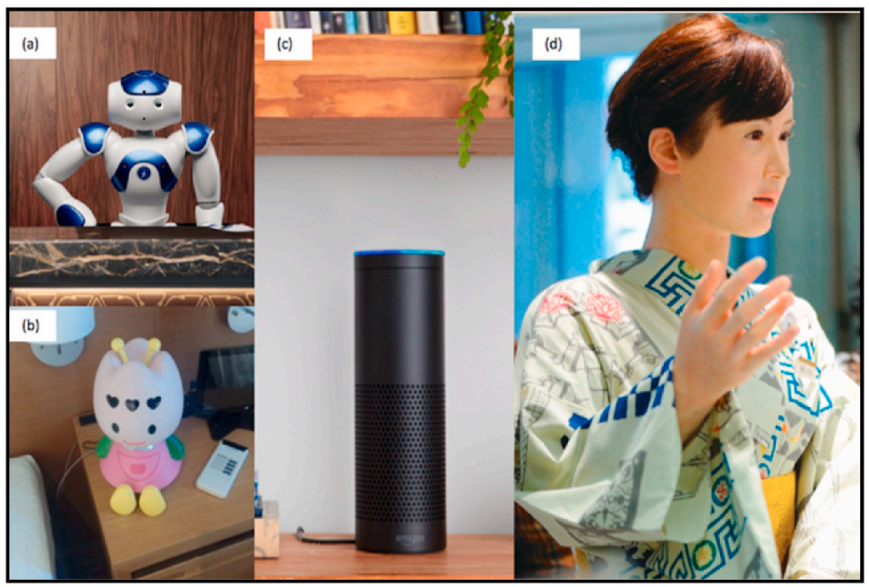

Fig. 5. Robots enhanced by AI: a Humanoid Connie; b Tulie agent; c Amazon Echo; d Android Aiko Chihira (adapted from Osawa et al. [54], Savage [65], Choi et al. [66], Amazon [67]).

\footnotetext{
${ }^{1}$ Similar humanoids are also used at Mandarin Oriental Las Vegas "Peper" [68].
} 
interaction [71,72]. The language processing of these humanoids is mainly mechanical; thus, the automatic speech emotion recognition is considered to be the AI next step to give them the capability of truly read human emotions and react accordingly [27]; (b) in-room hotel companions, such as "Tulie" from Henn-na hotel. This technology responds to the guests' requests via speech recognition, which allows devices to recognize voice information while the software interprets what is said and responds to customers' requests [54,73]; (c) another form to use AI-enabled technologies in the hospitality sector has been through the use of virtual agents and/or chatbots. For instance, Amazon's Echo is used by the Clarion Hotel Amaranten in Stockholm and acts as a butler, working through speech recognition and helping guests to request room services, providing online information assistance, etc. [74,75]; Ewardian Hotels also offer a chatbot service where the customer can request, for instance, assistance in finding the best restaurants in the area and any sort of tourist information [76]. Although not a part of the hospitality context, "Aiko Chihira" android is worth noticing given its physical characteristics. Aiko Chihira is an android developed by Toshiba Corporation which offers 6-min guidance to customers [77]. The interaction with customers is, however, very limited and for that reason its creators from Toshiba and Osaka University have planned to incorporate speech recognition and synthesis into the robot by 2020 [65]. Although more limited, because there is no or very little sign of AI capacity, we have to mention autonomous delivery robots, such as the self-navigate indoor "Relay" and "Wally" that are used to carry items to hotel rooms of the Holiday Inn Express hotels, Residence Inn by Marriott and Aloft [13], or "Jeno" and "Jena" from Hotel Jen, Singapore [25];

Overall, when compared to humans, the empathic and communicational skills of robots are still very limited, even with the incorporation of AI technologies. These advances in the hospitality sector must be viewed with caution, considering that they require a high level of interaction, particularly in the frontline services; therefore, in line with other academics, we also think that deeper empirical work is needed to question the current efficacy of using AI together with service robots in tourism [20].

\section{Methodology}

This article uses a systematic literature review methodology [78,79] because we intended to provide the best evidence possible in order to inform academics and professionals, while adopting a "replicable, scientific and transparent process" [80]. We selected Scopus as our source database due to its vast coverage of peer-reviewed articles [64] on $\mathrm{AI} /$ Robotics when compared to similar databases (i.e. Web of Science, B-On, EBSCO, ScienceDirect). As for the use of general-purpose search engines, such as Google Scholar, as it is not restricted to peer-reviewed articles, the Scopus option seemed more appropriate, as it increases the quality of the research, giving a greater confidence to the reader. Two independent searches using the keywords "robotics" and "artificial intelligence" carried out on March 6th' 2020 revealed that Scopus had a higher number of hits than Web of Science (12,050 vs 2135 hits). We decided to stick to a single source database because our priority is achieving a level of transparency that will allow for an easy reproduction of results [81]. For the purpose of this study, we conducted two searches on March 6th' 2020; the first used the keyword "service robots"

Table 1

Literature review.

\begin{tabular}{lllll}
\hline Scopus database & & & & \\
\hline Selected keywords & "Service robots" & & "Henn-na" & \\
\hline Search & Title-abstract-keywords & 4402 & All fields & 29 \\
Language & English & 4183 & English & 27 \\
Source type & Journals & 1160 & & \\
Document type & Articles & 1055 & & \\
Years & $2020-2017$ & 370 & & \\
\hline
\end{tabular}

in the fields Title, Abstract and Keywords; the second used the keyword "Henn-na" in All Search Fields (Table 1), including the title-abstract-keywords.

In both searches, we selected only papers written in English to avoid misinterpretation. If we had used different languages, it would naturally have been more difficult to understand and interpret the results.

In the first search, we selected journal articles since articles published in journals are typically more rigorous compared to, for example, conference proceedings or book chapters. We have only selected recent articles, i.e., published over the last three years and the first three months of 2020, so as to cover the current state-of-the-art.

As can be seen in Fig. 6, since 2017 there has been a significant increase in published articles. This was one of the reasons we chose these dates. This increase has been largely due to the need to develop human skills in robots, which is one of the aspects we will address in the discussion section. Fig. 6 also justifies the choice of our research topic since the number of publications has been growing exponentially over the last few decades and particularly over the last three years.

The second search was performed with the keyword "Henn-na" in all search fields and the only filter used was the language: all the articles had to be written in English. If we had applied too many filters, we would have narrowed the results more than what would have been desirable and, as a result, the information about the hotel would be unduly restricted. In addition to the search record, we did not exclude any article, as, to a greater or lesser extent, they were relevant to the investigation; we did not include any more articles than those selected. Therefore, our selection ended with a total of 397 peer-reviewed articles published in scientific journals.

The next step was to perform data analysis. To carry out such endeavor we used content analysis [82]. We started with reading all 397 selected articles so that we could become familiar with the most relevant concepts and ideas. In a second phase, we encoded similar terms, and, through their grouping, it was possible to identify categories and subcategories [83]. In a third phase, we ranked the categories and subcategories, identifying new patterns and relationships to reduce data and making sense of all the information [84]. Finally, we went through the entire categorization process until redundancies and contradictions were eliminated [39]. Once all phases were completed, we were able to get a holistic view of the pros and cons of using service robots in the frontline of the Henn-na hotel. To assist in the above process, we used a computer assisted qualitative data analysis software - NVivo 11 [85] which allowed us to encode a large amount of data $[86,87]$ and to identify patterns easily and promptly. In order to guarantee quality, unbiased review and reliability, the second author carried out an independent encoding process to make sure that the same results were achieved. During the independent encoding, some differences were identified and discussed until the authors reached a consensus. This allowed the results to be refined and, consequently, more solid and

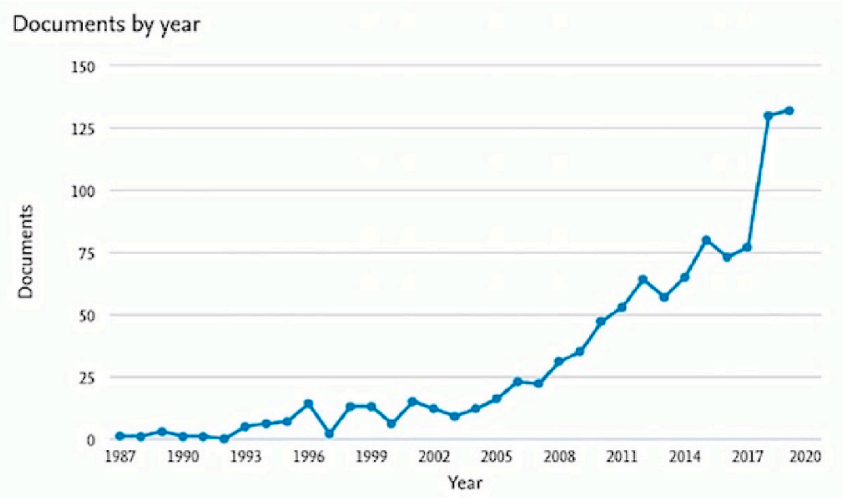

Fig. 6. Journal articles published by year (retrieved from Scopus database). 
reliable evidence was found. The entire process was ultimately reviewed by the other authors. As we encoded 397 references, we followed the decision of many other authors who conducted systematic reviews and decided not to list all the references $[64,88,89]$, and, therefore, save space with more useful information. A copy with the entire encoding process and a list of all manuscripts retrieved from Scopus can be provided upon request to the corresponding author.

\section{Findings and discussion}

In this section, we explore the pros and cons of the service robots at the Henn-na hotel, compared to frontline services workers. Next, we will combine the AI resources to understand the extent to which their existence influences human work. This section is based on the content analysis of the articles selected from the systematic literature review (Table 1), which is focused on the theme and on peer-reviewed journal articles, in contrast to the conceptual background (section 2) that focuses on fundamental definitions and theories.

\subsection{Service robots: perspectives in the hospitality industry}

Although relevant investigations have been carried out on the effect of service robots on guest rating [90], there are still no studies focusing on fully automated hospitality services. We believe that the absence of guest rating studies is probably due to the novelty of frontline automated services. In this regard, case studies like Henn-na hotel are stimulating the interest of both practitioners and academics and, thus, research on fully automated hospitality services is likely to increase.

Chan and Tung [90] found out that robotic services provided higher levels of sensorial (i.e. customers' visual impression) and intellectual (i. e. customer curiosity and problem-solving) experiences, but lower levels of affective experience than humans. The fact is that current technology has not yet reached the desired level of service delivery, but there is no evidence that an improved technology can't replace the emotional side of workers.

As we are experiencing an era in which the technological capacity to provide fully automated frontline services is increasing in the field of hospitality [91], it is predictable that service robots are likely to become gradually more social and, thus, will be able to overcome, or at least mitigate, the limitation identified by Chan and Tung [90].

Thus, to the best of our knowledge no study has yet focused on the performance of frontline robots through the lens of the main dimensions of services [23], or through the levels of intelligence associated with the execution of frontline tasks [27]. As such, our research tries to combine service dimensions and AI levels to leverage robots' capabilities and this can be relevant to provide useful guidance for hotel managers who are looking to improve their guest ratings.

It is evident that hospitality involves many different types of social robots and, therefore, there has been a widespread discussion within the academic community. In that regard, we identified three generic viewpoints: for instance, 1) Nakanishi et al. [53,92] carried out a research to investigate whether humanoid robots can engage in heartwarming interactions with hotel customers. Their results indicate that social robots enhance customer satisfaction with the whole service; 2 ) other authors are less enthusiastic about the use of social robots in empathetic interactions. An example is Osawa et al. [54], who does not exclude this possibility, arguing that "although human emotional labor seems difficult to simply replace with robot technologies, there is a possibility that human emotional labor can be replaced in a very complicated way" (p. $223)$; 3) the most skeptical positions refer that the technological gains of service robots to perform complex socio-emotional tasks are still a vision [19].

As Chan and Tung [90] state "among all levels of hotels, robotic service decreased affective experience. A possible reason for this result is the limitations of current robotic technology as service robots cannot imitate humans to the same extent in terms of emotions" (p. 466). In summary, as the technological capacity of robots progresses, their socio-emotional and intelligent capabilities also improve and, in that regard, it is natural that researchers have focused on the results of empathetic dimensions of HRI. Concomitantly, the number of investigations has grown (Fig. 6) in order to understand human reactions to robots, but these studies have focused on the perspective of the customer and not on the employee side, as mentioned by Ivanov et al. [93].

The Henn-na hotel, as we noted earlier, has incorporated some robotic elements into its operations [94] like robot receptionists who assumed anthropomorphic or zoomorphic characteristics [95]. Nevertheless, Henn-na ended up removing up to half of its robotic staff, since these robots were not advanced enough to carry out the social activities they were meant to. Understandably, this situation caused frustration among some of the hotel customers [96]. Overall, many guests at Henn-na hotels experienced disruptions because they were unable to communicate with robots due to language barriers, while another Henn-na guest felt that the technology "did not yet exist" because they could not help customers when they needed assistance [19,97]. Therefore, Henn-na returned to traditional human-provided services by combining them with android receptionists - human-robot collaboration (HRC). As a rule, guests start their journey with the help of a human receptionist and then head for an automated kiosk where robots greet and assist them in the check-in process. This HRC is the reason why 7 employees are able to manage a 98-room hotel when a conventional hotel of a similar scale needs at least 30 employees to function properly [98].

Although Henn-na has dismissed part of its robotic workforce, the use of service robots should not be abandoned, but rather rethought; compared to conventional hotels, they have reduced operational costs and, according to media reports, some customers have stayed an extra night in the hotel in order to experience the hotel robots [99].

Table 2 presents a summary of section 5.1. Therefore, it is evident that the current literature still identifies service robots as capable of providing high sensorial and intellectual experiences, but having low levels of affective experience. To mitigate the mentioned limitation, most authors recommend the use of alternatives, such as the use of service robots, while these operate in collaboration with humans (HRC), or the use of social robots, which are better prepared to participate in heartwarming interactions, despite the fact that the latter option is not yet consensual in the literature.

Before moving on to the next section, we need to make a clear distinction between HRC and HRI. According to Galin and Meshcheryakov [100], the human-robot interaction (HRI) can be seen from two different perspectives: the first shows the interaction in a shared workspace without direct human-robot contact; the second sees it as a joint process of performing tasks, taking into account adjusted robot movements in accordance to human labor. So far, the design and development of robotic agents (HRI) to be implemented in the real world requires an appropriate robot architecture that will have to go beyond the efficiency achieved in the laboratory [101,102] Regarding the HRC, Galin and Meshcheryakov [100] refer to human-robot collaboration as a

Table 2

Service robots in the hospitality industry.

\begin{tabular}{ll}
\hline Resume of relevant categories & Main authors \\
\hline $\begin{array}{l}\text { Service robots provide high levels of sensorial and } \\
\text { intellectual experiences, and low levels of } \\
\text { affective experience }\end{array}$ & Chan and Tung [90] \\
$\begin{array}{l}\text { Social robots are still identified as having limited } \\
\text { ability to interact with customers, most } \\
\text { recommendations are for using robots in } \\
\text { collaboration with humans }\end{array}$ & $\begin{array}{l}\text { Tung and Au [97]; Kikuchi } \\
\text { [98]; Zhang et al. [99] }\end{array}$ \\
$\begin{array}{l}\text { Social robots are becoming more empathetic and } \\
\text { capable of engaging in heartwarming interactions } \\
\text { [not consensual] }\end{array}$ & $\begin{array}{l}\text { Osawa et al. [54]; Nakanishi } \\
\text { et al. [53,92] }\end{array}$ \\
\hline
\end{tabular}


complement that does not replace human professionals. A clear example of such collaboration is, for instance, like having a doctor receiving AI advice to assist in decision making, instead of having a robot doctor performing the operation. Therefore, humans and robots (collaborative robots - cobots) work together to achieve the same objective, but they are not integrated in the same workload.

\subsection{Human-robot collaboration: service robots $v$ s humans in the frontline}

The focus in this section is on frontline robots and their relationship with humans. In this context, emphasis is placed on collaboration, rather than interaction. Service robots have evolved in several domains, from one-function automatons to intelligent systems of versatile resources and are sharing the same space and tasks with human beings [103]. In that regard, the service industry has been at the forefront of adapting new technologies to improve consumer experience, particularly in hospitality where an infusion of AI technologies has made relevant contributions [13]. Ivanov et al. [1], for instance, have made remarkable efforts to strengthen the role of robotics in tourism and hospitality, and claim that robotics and AI can become a reliable alternative to human employees. However, they also advice that not all services can and should be automated since "at the end of the day it is the economic efficiency, the customer experience, the company's competitiveness and other factors that will determine whether to automate and robotize the service delivery process" (p. 1512). Perhaps this is what happened with the Henn-na hotel when it was forced to replace part of the robotic force of the frontline services with human employees who are currently working in a HRC environment. In this sense, frontline tasks, such as receiving customers who require empathic interactions or helping a guest solving a problem caused by a service provided are to be performed primarily by human receptionists as they require a strong empathic relationship that can't be provided by androids. The activities of frontline robots started to be performed in collaboration with human receptionists; this collaboration is probably due to the lack of investment in AI that could make these androids capable of interpreting, processing and responding to customer needs. This difficulty is due above all to the initial investment needed to create the hotel, a process which goes well beyond technology. However, if Henn-na hotel wants to remain at the forefront, it will have to make continuous customer-centric investments, not only because of the short cycles of technological innovation, but also because the customers who come to these hotels on a regular basis are increasingly demanding in terms of interaction with the latest technologies [91,104].

It is likely that the Henn-na hotel will have to abandon the HRC approach in the future and move towards a new stage in which greater focus will be placed on social robots enhanced with advanced artificial and emotional intelligence technologies.

Currently, and despite all the progress made in the use of AI in hospitality services, we can't be sure we have already reached the desired stage, since the advances in the field of social robots [13] seem quite incomplete so far. From the literature review carried out, we were able to find some empirical developments on the application of AI-enabled technologies for service delivery, which gave us several perspectives on its applicability. Some authors have surveyed radiologists who expressed their dissatisfaction with AI technology because, in their opinion, it provided inaccurate reports compared to traditional services $[105,106]$. On the other hand, practitioners, mentioned in the McKinsey Global Institute Report [107], argued just the opposite, and Gartner et al. [108] stated that AI methods and programming-based resources increased the hospital's contributions margin. So, bearing in mind that AI can improve service robots' capabilities in the healthcare sector, what should we expect from their implementation in the hospitality sector?

According to Wirtz et al. [23] whose work was useful to map the needs and expectations of customers when it comes to the capabilities of robots, it is quite clear that in hospitality there are tasks of low analytical-cognitive complexity and others of high emotional complexity. For that reason, and due to the evident limitations presented by social robots previously addressed in this article (e.g. Peper, Connie), frontline roles and duties will have to be primarily delivered by humans or be carried out in collaboration and not assigned to fully automated environments. This is entirely understandable since a preponderant part of the hospitality sector generates empathic emotions that are relevant to the customers' satisfaction and service loyalty. On the other hand, service robots that have been used in mechanical and standardized operations that do not require a high level of interpersonal demand have apparently been successful in Henn-na where there are few reports of their ineffectiveness.

In light of the above, there are complex issues, such as complaint mediation procedures for instance, that require skills only human employees possess, or that can ultimately be carried out by highly collaborative human-robot teams. Reis et al. [109] argue that companies are adopting strategies that involve the use of frontline employees to solve complex service failures because human employees are much more reliable to carry out service recovery activities. In some cases, these employees may complement their activities with the support of offline technologies. Tung and Law [37] went further as they uncover new opportunities, such as "human operators to be telepresent on screen from co-present robots" [37, p. 17]. This seems a reliable alternative when dealing with complex services that exceed the capabilities of frontline employees. At the end of the line, advances in robotics and AI technologies can create extensive opportunities for the use of automation in the hospitality segment, in this field professionals can aid in identifying tasks that can be replaced by machines, however more empirical research is needed in this regard [37,93]. This is in clear contrast to the situation of the Henn-na hotel that was unable to perform empathic tasks using anthropomorphic robots. This attempt caused negative reactions and led to negative experiences among guests who considered that robots were nothing but "a gimmick" or a "marketing stunt".

In fact, what happens is that interactions with fully automated robots in the frontline hospitality services are usually considered insufficient, as they do not have the AI capabilities to mimic human-oriented perceptions and dimensions and, therefore, their action is more than often carried out with high levels of impersonality and that is why "these services, in general, will by and large continue to be delivered by people" [23, p. 919].

As Table 3 summarizes section 5.2, it shows that AI technologies are starting to play a significant role in adding new competencies to service robots, but at their current stage of development, it makes more sense to adopt HRC systems.

\subsection{Towards the implementation of social robots: challenges and implications}

In this section, the goal is to discuss the hospitality services of the Henn-na hotel in the light of the impact of service robots at three levels

Table 3

Service robots and human interactions in the frontline.

\begin{tabular}{ll}
\hline Resume of relevant categories & Main authors \\
\hline $\begin{array}{l}\text { In the frontline services, the emphasis is placed on } \\
\text { collaboration, rather than interaction }\end{array}$ & Ivanov et al. [1,91] \\
$\begin{array}{l}\text { Interactions with fully automated robots in the } \\
\text { frontline hospitality services are still } \\
\text { insufficient }\end{array}$ & $\begin{array}{l}\text { Tung and Law [37]; Ivanov } \\
\text { et al. [93] }\end{array}$ \\
$\begin{array}{l}\text { Developments in the field of AI-enabled } \\
\text { technologies for service delivery have brought } \\
\text { new opportunities in the field of hospitality }\end{array}$ & $\begin{array}{l}\text { Ivanov et al. [1]; Murphy et al. } \\
\text { Until robots are not enabled with advanced AI } \\
\text { technologies, the hospitality services will } \\
\text { continue to be collaborative (HRC) }\end{array}$ \\
\end{tabular}


(micro, meso and macro), as well as the types of intelligence (mechanical, thinking and feeling), as seen in Table 4.

As mentioned earlier, we will consider the following:

- Human employees in frontline services show a high degree of personalization and heterogeneous emotional relationship. Thus, we consider that frontline services are highly cognitive and socioemotional, so the use of HRC systems is highly recommended;

- Services of high consistency and analytical-cognitive complexity must be performed by service robots.

Table 4 shows that Henn-na hotel employees are better prepared to deliver services than service robots ( 5 positive items against 3 ). This preliminary analysis shows why frontline robots were replaced by HRC systems [111]. From the point of view of micro, meso and macro levels, we present the following discussion.

Micro level: the first point presents the Henn-na hotel employees' profile. They are capable of engaging in out of the box thinking and of properly responding to the customers' specific needs. On the other hand, when service robots are used to perform feeling intelligence activities, the ability to respond to customers' needs is poor. In this context, the use of social robots is essential, because they are able to learn through interaction with customers and respond appropriately.

On the other hand, the use of employees requires continuous training and education, while service robots only need to be (re)programmed. Social robots have high capability to learn and adapt to new situations. One key issue has to do with emotions, and in this particular aspect human employees are much better than robots, despite all the significant improvements made to social robots and that may bring them closer to humans in a not too distant future.

Nevertheless, customers view employees as resources that are able to deliver customized services, while service robots have the ability to provide consistent and high quality services. From the point of view of thinking intelligence, it is likely that social robots, through relational experience with their "fellow" human employees (in HRC), will gain greater work capacity and will thus be able to adapt their behaviours to the customers' needs. These robots' ability to learn, both from customers and employees, is critical to reduce customer frustration and disappointment, especially if guests have to face the same challenge multiple times. For this reason, the development of new technologies related to receptionist robots, such as social interactive robots (SIR) that are equipped with social features and social assistive robots (SAR) that are able to collaborate and provide assistance to humans in social interactions with customers, is of the utmost importance. Under these circumstances, robots have almost reach human-like operating capacity as they are able to engage in deep acting activities (i.e. feeling intelligence).

Meso level: If, on the one hand, service robots that don't rely on AI technologies are unlikely to become a key source of competitive advantage, at least in the medium and long term [23], on the other hand, for hotels that operate in innovative and extremely competitive markets, social robots can become a very important asset. Although they may represent a heavy investment at an early stage, humans are still the best alternative to the previous option since they are capable of providing a strong competitive advantage. Future opportunities for social robots lie, for instance, with monitoring and assistance services for the elderly and with the collection of knowledge about feeling intelligence, which will eventually be transferred to hospitality services. Henn-na hotel has a good advantage since it was the first to automate its processes and to receive feedback from customers on its robotic technologies. This early choice places the hotel in a privileged position, as long as it keeps innovating.

Macro level: According to Olszewska et al. [119], the efficiency of human activities is measured by the time required to carry them out and their relevance to customers. Although hospitality work is seasonal [120], robots are seen as a reliable solution to help hotels handle peak demand [28]. In addition to this aspect, the time for tasks to be performed by a robot is shorter and cheaper [119] and, for this reason, one of the greatest social concerns has to do with the risk of human unemployment caused by robots [13,121] and/or AI [24]. Other relevant social concerns are related to privacy [11,113], data protection [122] or ethical issues [119], which can hinder the implementation of social robots. For example, when robots are used $24 \mathrm{~h}$ a day, 7 days a week, in an environment for many weeks, they acquire a significant amount of data from users during social interaction, a situation that is difficult or almost impossible to avoid [122]. Aspects related to such concern may be a target for future research.

\section{Concluding remarks}

This section aims to provide a comprehensive view of the outcomes. It places special focus on theory and practice, research limitations and prospects for further research. The latter is meant to encourage researchers to follow up on social robotics research.

\subsection{Implications for theory and practice}

More and more hotels are trying to include robots in their frontline services, but only a few have managed to do so. What we know so far is that the literature on the topic presents several perspectives and, if some authors suggest that humanoid robots can engage in heartwarming interactions with hotel customers [53,92], others are slightly more skeptical and claim that the technological gains from service robots that are expected to perform tasks that involve complex socio-emotional interactions are still a vision. Therefore, despite all academic efforts, there is still no consensus in the literature on the widespread use of social robots in the hospitality industry, at least at this stage of their technological development. Even though hospitality does involve many different types of social robots, the academic community seems to be more interested in addressing a specific kind of interaction, rather than focusing on more general applications.

Anyway, in our understanding, managers should be cautious when evaluating how to integrate robots in frontline services, mainly because, in the context of the hotel frontline, the activities carried out essentially require the use of empathic intelligence and are, therefore, much more difficult to be delivered by machines. However, there are opportunities that can still be explored in the hospitality sector. One of the elementary characteristics of hospitality services is co-production [97] and, in this context, Henn-na hotel was the first to automate its entire service process and to receive the first feedback from customers on its HRC which places the hotel in a privileged position, assuming that they continue to innovate. This is also an opportunity for other hotels that might be interested in investing in robotic services as they can focus on the failures or the successes of the Henn-na hotel and learn the best way to implement such service. Thus, organizations will have to decide if technological advances are enough to enable AI to completely replace human labor with socially integrative robots capable of performing necessary emotional tasks or if they should invest in balanced systems (i. e. HRC). This research also provides a contribution to theory, as the technologies used by the first fully automated hotel (Henn-na) were upgraded and are now more efficient. Data analysis has contributed to expose the presence of several social robot types, i.e. interactive or assistive robots, and helped clarify the use of robotized technologies in the hospitality frontline service delivery. Bearing all this in mind, Henn-na has chosen to use a HRC which is apparently still functioning. Based on the analysis of the existing literature, the use of HRC systems reinforces the fact that robots are not used to replace entire jobs, but human tasks. This key finding helps to demystify the social fear associated with the theory of job replacement and, although it was previously identified by Osawa et al. [54], it seems to be gaining more strength in the academic community. 
Table 4

The path to effective social robots: impact levels (micro, meso and macro) and types of intelligence (mechanical, thinking and feeling) [Adapted from Murphy et al. [11], Huang and Rust [27], Rosete et al. [19]).

\begin{tabular}{|c|c|c|c|c|c|c|c|}
\hline $\begin{array}{l}\text { Impact } \\
\text { Levels }\end{array}$ & & $\begin{array}{l}\text { Service } \\
\text { Employees }\end{array}$ & $\begin{array}{l}\text { Service } \\
\text { Robots } \\
\text { Rear } \\
\text { services }\end{array}$ & $\begin{array}{l}\text { Henn-na } \\
\text { Hotel }\end{array}$ & $\begin{array}{l}\text { Social Robots } \\
\text { Human-centered | Frontline } \\
\text { services }\end{array}$ & $\begin{array}{l}\text { Types of } \\
\text { Intelligence }\end{array}$ & Results \\
\hline \multirow[t]{5}{*}{ Micro } & \multirow[t]{3}{*}{ Employees } & $\begin{array}{l}+ \\
\text { Looking for } \\
\text { creative and } \\
\text { practical } \\
\text { solutions }\end{array}$ & $\begin{array}{l}\text { Little ability to } \\
\text { think outside } \\
\text { the box }\end{array}$ & $\begin{array}{l}\text { Reduced customer } \\
\text { relationship [94] }\end{array}$ & $\begin{array}{l}\text { Application of human- } \\
\text { human interaction principles } \\
\text { to human-machine } \\
\text { interactions, the personality } \\
\text { is an important aspect of } \\
\text { design [11] in order to } \\
\text { improve customer and robots } \\
\text { relationship }\end{array}$ & $\begin{array}{l}\text { Feeling } \\
\text { intelligence }\end{array}$ & $\begin{array}{l}\text { It is crucial that robots have } \\
\text { human-like social interaction } \\
\text { skills and learn from them [117, } \\
118]\end{array}$ \\
\hline & & $\overline{-}$ Need training & $\begin{array}{l}+ \\
\text { Upgradable and } \\
\text { system-wide }\end{array}$ & $\begin{array}{l}\text { Education is provided so } \\
\text { that any employee can } \\
\text { handle such work [54, p. } \\
242]\end{array}$ & $\begin{array}{l}\text { We have not identified any } \\
\text { evidence of technologies that } \\
\text { upgrade the social robots. } \\
\text { We are convinced that these } \\
\text { technologies are related to e. } \\
\text { g. deep learning } \\
\text { technologies. }\end{array}$ & $\begin{array}{l}\text { Mechanical } \\
\text { intelligence }\end{array}$ & \\
\hline & & $\begin{array}{l}+ \\
\text { Identify the } \\
\text { customer } \\
\text { emotions and } \\
\text { respond } \\
\text { accordingly }\end{array}$ & $\begin{array}{l}- \\
\text { Pattern } \\
\text { recognition }\end{array}$ & $\begin{array}{l}\text { The employees feel the } \\
\text { client emotions, while } \\
\text { service robots do not [54] }\end{array}$ & $\begin{array}{l}\text { Greater capacity for } \\
\text { socialization, because social } \\
\text { robots were firstly designed } \\
\text { to enter in our lives as } \\
\text { companions and assistants } \\
\text { for the elderly }[1,113]\end{array}$ & $\begin{array}{l}\text { Feeling } \\
\text { intelligence }\end{array}$ & $\begin{array}{l}\text { There have been significant } \\
\text { advances in the development of } \\
\text { robots that identify human } \\
\text { emotions and respond in } \\
\text { accordance with what would be } \\
\text { expected in a human being }\end{array}$ \\
\hline & \multirow[t]{2}{*}{ Customer } & $\begin{array}{l}+ \\
\text { Have the ability } \\
\text { to customize } \\
\text { services }\end{array}$ & $\begin{array}{l}+ \\
\text { If } \\
\text { programmable, } \\
\text { they can deliver } \\
\text { services at scale, } \\
\text { with consistent } \\
\text { quality and } \\
\text { performance }\end{array}$ & $\begin{array}{l}\text { The Japanese considers } \\
\text { cleaning guest rooms as a } \\
\text { human work, while robots } \\
\text { cleans common facilities } \\
\text { such as corridors [54, p. } \\
241]\end{array}$ & $\begin{array}{l}\text { Researchers have already } \\
\text { designed human-conscious } \\
\text { deliberative architectures for } \\
\text { social robots for decision- } \\
\text { making and planning in } \\
\text { collaborative tasks, where } \\
\text { humans work together in the } \\
\text { same space with robots to } \\
\text { accomplish a shared task } \\
\text { [114] }\end{array}$ & $\begin{array}{l}\text { Thinking } \\
\text { intelligence }\end{array}$ & $\begin{array}{l}\text { Due to experience, robots are } \\
\text { likely to acquire the ability to } \\
\text { learn and respond to new } \\
\text { customer stimuli. In this sense, } \\
\text { HRC is expected to have } \\
\text { contexts of proximity to the } \\
\text { customer in support or rear } \\
\text { services }\end{array}$ \\
\hline & & $\begin{array}{l}+ \\
\text { Can engage in } \\
\text { deep acting }\end{array}$ & $\begin{array}{l}- \\
\text { Superficial } \\
\text { interaction }\end{array}$ & $\begin{array}{l}\text { Robots have low or limited } \\
\text { communication capacity, } \\
\text { this is currently } \\
\text { complemented by human } \\
\text { receptionists }[54,97,110]\end{array}$ & $\begin{array}{l}\text { Some robotic receptionists } \\
\text { can be seen as: Socially } \\
\text { Interactive Robots (SIR) } \\
\text { equipped with social } \\
\text { interaction skills as main } \\
\text { features, or as Socially } \\
\text { Assistive Robots (SAR), since } \\
\text { they aim to provide } \\
\text { assistance to human users } \\
\text { through social interactions } \\
\text { [5] }\end{array}$ & $\begin{array}{l}\text { Feeling } \\
\text { intelligence }\end{array}$ & $\begin{array}{l}\text { Social robots, such as SIR and } \\
\text { SAR are expected to be an } \\
\text { important source of } \\
\text { competitiveness and are } \\
\text { expected to have capabilities } \\
\text { close to humans in a near future }\end{array}$ \\
\hline Meso & Markets & $\begin{array}{l}+ \\
\text { Are seen as a } \\
\text { competitive } \\
\text { advantage }\end{array}$ & $\begin{array}{l}- \\
\text { Unlikely to be a } \\
\text { source of } \\
\text { competitive } \\
\text { advantage }\end{array}$ & $\begin{array}{l}\text { Henn-na is now using a HRC } \\
\text { system that currently works } \\
\text { with fewer limitations than a } \\
\text { full automated system [111] }\end{array}$ & $\begin{array}{l}\text { Social robots are now } \\
\text { appearing in the real world } \\
\text { and we are seeing a growing } \\
\text { market in service industry for } \\
\text { robots which interact with } \\
\text { customers [115] }\end{array}$ & $\begin{array}{l}\text { Feeling } \\
\text { intelligence }\end{array}$ & \\
\hline \multirow[t]{3}{*}{ Macro } & \multirow[t]{3}{*}{ Society } & $\begin{array}{l}- \\
\text { Often do low- } \\
\text { value tasks }\end{array}$ & $\begin{array}{l}+ \\
\text { Suitable for } \\
\text { unattractive and } \\
\text { mundane } \\
\text { services }\end{array}$ & $\begin{array}{l}\text { In some western countries } \\
\text { cleaning activities are } \\
\text { considered a routine and } \\
\text { unattractive job }\end{array}$ & $\begin{array}{l}\text { The recognition of a } \\
\text { community's social needs is } \\
\text { important for companies and } \\
\text { this meaning also extends to } \\
\text { social robotics [116] }\end{array}$ & $\begin{array}{l}\text { Mechanical } \\
\text { intelligence }\end{array}$ & $\begin{array}{l}\text { As in the manufacturing } \\
\text { industry, robots are likely to } \\
\text { increasingly contribute to } \\
\text { freeing humans to perform } \\
\text { value-added tasks; however, if } \\
\text { this evolution is very marked, it } \\
\text { is likely to create more pressure } \\
\text { on human unemployment }\end{array}$ \\
\hline & & $\begin{array}{l}\text { Service delivery } \\
\text { is more } \\
\text { expensive }\end{array}$ & $\begin{array}{l}+ \\
\text { Services at } \\
\text { reduced prices } \\
\text { and highly } \\
\text { standardized }\end{array}$ & $\begin{array}{l}\text { The time spent by robots is } \\
\text { less expensive [54, p. 242] } \\
\text { and in some cases, robots } \\
\text { can be useful in reducing the } \\
\text { lower added-value human } \\
\text { workload [112] }\end{array}$ & & $\begin{array}{l}\text { Mechanical } \\
\text { intelligence }\end{array}$ & $\begin{array}{l}\text { In addition to the financial } \\
\text { matters, there are also other } \\
\text { concerns related to robotic and } \\
\text { automated systems, such as the } \\
\text { privacy and ethical issues, } \\
\text { which are very relevant in our } \\
\text { opinion; therefore, there is an } \\
\text { urgent need to develop new } \\
\text { ontological patterns [119] }\end{array}$ \\
\hline & & \multicolumn{4}{|c|}{ Employees: +5 items $\&-3$ items $\mid$ Robots: +4 items $\&-4$ items } & \multicolumn{2}{|c|}{ Robots will have a positive outcome in all levels } \\
\hline
\end{tabular}




\subsection{Limitations}

This systematic literature review has some limitations, firstly due to its nature and, secondly, due to the options taken during the course of the research. Regarding its nature, the Scopus database is constantly being updated and, therefore, this article is based on literature from a specific time interval i.e. from 2017 until the first quarter of 2020; moreover, for quality reasons our sample focused on scientific articles but we came to realize that some quality manuscripts (e.g. books) may have eventually been left behind. Concerning the research options, while the keywords choice influences the result, we believe that this review has its value since it synthesizes a vast set of articles and provides a holistic view of the phenomenon under study. Still, in relation to the keywords, we selected "service robots" instead of for example "social robots", as our intention was to take small steps, one at a time, towards more contemporary concepts. To the best of our knowledge, this is the first systematic review on service robots in the frontline of fully automated hotels, so it would be more cautious to move towards the service robots' concept instead of focusing on a more specific subset. To mitigate the need for deeper knowledge on social robots, we have referred the need for further research in order to conduct more in-depth studies on this topic.

\subsection{Guidelines for future research}

While notable theoretical studies have been developed in hospitality and tourism applications and automation [123,124], it is now advisable to prepare the basis for empirical studies, such as, for example, a guest-rating analysis. In particular, by keeping on following the evolution of Henn-na hotel and its customers' feedback to better comprehend and improve autonomous service delivery according to customers' needs and expectations. On the other hand, it might be better to move forward with empirical studies on social robots, instead of focusing almost exclusively on service robots, given that social robots will probably represent the next evolutionary step for frontline services. We also believe that studies on social robots in frontline services are necessary to find appropriate, manageable and replicable solutions for hotel services, particularly in a context where complex cognitive and emotional tasks are required.

\section{Acknowledgments}

We would like to thank the anonymous reviewers for the time devoted in providing insightful recommendations that helped to improve this article in many ways. Nuno Melão is funded by National Funds through the FCT - Foundation for Science and Technology, I.P., within the scope of the project Ref. UIDB/05583/2020. We would like to thank the Research Centre in Digital Services (CISeD) and the Polytechnic of Viseu for their support.

\section{References}

[1] S.H. Ivanov, C. Webster, K. Berezina, Adoption of robots and service automation by tourism and hospitality companies, Revista Turismo e Desenvolvimento 27 (28) (2017) 1501-1517.

[2] M. Decker, M. Fischer, I. Ott, Service robotics and human labor: a first technology assessment of substitution and cooperation, Robot. Autonom. Syst. 87 (2017) 348-354.

[3] D. Belanche, L.V. Casaló, C. Flavián, J. Schepers, Service robot implementation: a theoretical framework and research agenda, Serv. Ind. J. 40 (3-4) (2020) 203-225.

[4] K. Engelhardt, Service robotics and artificial intelligence: current research and future directions, ISA (Instrum. Soc. Am.) Trans. 29 (1) (1990) 31-40.

[5] F. Bazzano, F. Lamberti, Human-robot interfaces for interactive receptionist systems and wayfinding applications, Robotics 7 (3) (2018) 56.

[6] D. David, C. Costescu, S. Matu, A. Szentagotai, A. Dobrean, Developing joint attention for children with autism in robot-enhanced therapy, International Journal of Social Robotics 10 (5) (2018) 595-605.
[7] D. Portugal, P. Alvito, E. Christodoulou, G. Samaras, J. Dias, A study on the deployment of a service robot in an elderly care center, International Journal of Social Robotics 11 (2) (2019) 317-341.

[8] S.N. Yoon, D. Lee, Artificial intelligence and robots in healthcare: what are the success factors for technology-based service encounter? Int. J. Healthc. Manag. 12 (3) (2019) 218-225.

[9] E. Broadbent, D.A. Feerst, S.H. Lee, H. Robinson, J. Albo-Canals, H.S. Ahn, B. MacDonald, How could companion robots be useful in rural schools? International Journal of Social Robotics 10 (3) (2018) 295-307.

[10] J. Ding, R.Z. Lin, Z.Y. Lin, Service robot system with integration of wearable Myo armband for specialized hand gesture human-computer interfaces for people with disabilities with mobility problems, Comput. Electr. Eng. 69 (2018) 815-827.

[11] J. Murphy, U. Gretzel, J. Pesonen, Marketing robot services in hospitality and tourism: the role of anthropomorphism, J. Trav. Tourism Market. 36 (7) (2019) 784-795.

[12] K. Dautenhahn, Social intelligence robots: dimensions of human-robot interaction, Phil. Trans. Biol. Sci. 362 (1480) (2007) 679-704.

[13] L. Lu, R. Cai, D. Gursoy, Developing and validating a service robot integration willingness scale, Int. J. Hospit. Manag. 80 (2019) 36-51.

[14] C. Prentice, S.D. Lopes, X. Wang, Emotional intelligence or artificial intelligencean employee perspective, J. Hospit. Market. Manag. (2019) 1-27, https://doi. org/10.1080/19368623.2019.1647124.

[15] B.R. Duffy, Anthropomorphism and the social robot, Robot. Autonom. Syst. 42 (3-4) (2003) 177-190.

[16] C. Bartneck, D. Kulić, E. Croft, S. Zoghbi, Measurement instruments for the anthropomorphism, animacy, likeability, perceived intelligence, and perceived safety of robots, International journal of social robotics 1 (1) (2009) 71-81.

[17] IJCHM, Artificial intelligence in hospitality and tourism. https://www.emer aldgrouppublishing.com/journal/ijchm/artificial-intelligence-hospitality-and-to urism, 2020. (Accessed 17 September 2020).

[18] Jst, Digitalization and sustainability in the tourism and hospitality sectors. https: //think.taylorandfrancis.com/special_issues/sustainable-tourism-digitalization/, 2020. (Accessed 17 September 2020).

[19] A. Rosete, B. Soares, J. Salvadorinho, J. Reis, M. Amorim, Service robots in the hospitality industry: an exploratory literature review, in: International Conference on Exploring Services Science, Springer, Cham, 2020.

[20] R. de Kervenoael, R. Hasan, A. Schwob, E. Goh, Leveraging human-robot interaction in hospitality services: incorporating the role of perceived value, empathy, and information sharing into visitors' intention to use social robots, Tourism Manag. 78 (2020) 104042.

[21] M.R. Solomon, C. Surprenant, J.A. Czepiel, E.G. Gutman, A role theory perspective on dyadic interactions: the service encounter, J. Market. 49 (1) (1985) 99-111.

[22] S. Ivanov, C. Webster, Robots in tourism: a research agenda for tourism economics, Tourism Econ. (2019), https://doi.org/10.1177/1354816619879583.

[23] J. Wirtz, P. Patterson, W. Kunz, T. Gruber, V. Lu, S. Paluch, A. Martins, Brave new world: service robots in the frontline, Journal of Service Management 29 (5) (2018) 907-931.

[24] M.H. Huang, R.T. Rust, Artificial intelligence in service, J. Serv. Res. 21 (2) (2018) 15-172.

[25] Y. Choi, M. Choi, OhM, S. Kim, Service robots in hotels: understanding the service quality perceptions of human-robot interaction, J. Hospit. Market. Manag. (2019) 1-23, https://doi.org/10.1080/19368623.2020.1703871.

[26] R. Rust, M. Huang, The service revolution and the transformation of marketing science, Market. Sci. 33 (2) (2014) 206-221.

[27] M.H. Huang, R.T. Rust, Engaged to a robot? The role of AI in service, J. Serv. Res. (2020), https://doi.org/10.1177/1094670520902266.

[28] C. Kuo, C. Chen, C. Tseng, Investigating an innovative service with hospitality robots, Int. J. Contemp. Hospit. Manag. 29 (5) (2017) 1305-1321.

[29] D. Belanche, L.V. Casaló, C. Flavián, Customer's acceptance of humanoid robots in services: the moderating role of risk aversion, in: Marketing and Smart Technologies, Springer, Singapore, 2020, pp. 449-458.

[30] O.H. Chi, G. Denton, D. Gursoy, Artificially intelligent device use in service delivery: a systematic review, synthesis, and research agenda, J. Hospit. Market. Manag. (2020) 1-30, https://doi.org/10.1080/19368623.2020.1721394.

[31] J. Bowen, C. Morosan, Beware hospitality industry: the robots are coming, Worldwide Hospitality and Tourism Themes 10 (6) (2018) 726-733.

[32] R. Kachouie, S. Sedighadeli, R. Khosla, M.T. Chu, Socially assistive robots in elderly care: a mixed-method systematic literature review, Int. J. Hum. Comput. Interact. 30 (5) (2014) 369-393.

[33] L. Gong, C. Nass, When a talking-face computer agent is half-human and halfhumanoid: human identity and consistency preference, Hum. Commun. Res. 33 (2) (2007) 162-193.

[34] L. Royakkers, R. Van Ester, Just Ordinary Robots: Automation from Love to War, CRC Press, 2015, https://doi.org/10.1201/b18899.

[35] T. Fong, I. Nourbakhsh, K. Dautenhahn, A survey of social interactive robots, Robot. Autonom. Syst. 42 (3-4) (2003) 143-166.

[36] K. Dautenhahan, Human-robot interaction, in: Encyclopedia of Human-Computer Interaction, Springer, New York, 2013.

[37] V.W. Tung, R. Law, The potential for tourism and hospitality experience research in human-robot interactions, Int. J. Contemp. Hospit. Manag. 29 (1) (2017) 2498-2513.

[38] Y. Lee, K.A. Kozar, K.R. Larsen, The technology acceptance model: past, present, and future, Commun. Assoc. Inf. Syst. 12 (1) (2003) 50. 
[39] J. Reis, N. Melão, The path to digital transformation: overcoming prejudice in the digital era with service operations, Int. J. Serv. Oper. Manag. (2020), https://doi. org/10.1504/IJSOM.2020.10023943.

[40] K. Liaw, S. Driver, M.R. Fraune, Robot sociality in human-robot team interactions, in: International Conference on Human-Computer Interaction, Springer, Cham, 2019, pp. 434-440, https://doi.org/10.1007/978-3-030-30712-753.

[41] J. Van Doorn, M. Mende, S.M. Nobble, J. Hulland, A.L. Ostrom, D. Grewal, J. A. Petersen, Domo arigato, Mr. Roboto: emergence of automated social presence in organizational frontlines and customers' service experiences, J. Serv. Res. 20 (1) (2017) 43-58.

[42] L. Damiano, P. Dumouchel, H. Lehmann, Towards human-robot affective coevolution overcoming oppositions in construction emotions and empathy, International Journal of Social Robotics 7 (1) (2015) 7-18.

[43] T. Nomura, T. Kanda, Rapport-expectation with a robot scale, International Journal of Social Robotics 8 (1) (2016) 21-30.

[44] T. Denning, C. Matuszek, K. Koscher, J.R. Smith, T. Kohno, A spotlight on security and privacy risks with future household robots: attacks and lessons, in: Proceedings of 11th International Conference on Ubiquitous Computing, 2009, pp. 105-114.

[45] F.E. Fernandes, G. Yang, H.M. Do, W. Sheng, Detection of privacy-sensitive situations for social robots in smart homes, in: 2016 IEEE International Conference on Automation Science and Engineering (CASE, IEEE, 2016, pp. 727-732.

[46] U. Pagallo, Robots in the cloud with privacy: a new threat to data protection? Comput. Law Secur. Rep. 29 (5) (2013) 501-508.

[47] M.O. Qureshi, R.S. Syed, The impact of robotics on employment and motivation of employees in the service sector, with special reference to healthcare, Safety and Heath at Work 5 (4) (2014) 198-202.

[48] M. Huang, R. Rust, V. Maksimovic, The feeling economy: managing the next generation of artificial intelligence (AI), Calif. Manag. Rev. 61 (4) (2019) 43-65.

[49] ISRE, International society for research on emotion: welcome to ISRE. http://www.isre.org, 2020. (Accessed 6 March 2020).

[50] CERE, Consortium of European research on emotion: home. http://www.cer e-emotionconferences.org, 2020. (Accessed 6 March 2020).

[51] University of Amsterdam, Amsterdam interdisciplinary centre for emotion (AICE https://aice.uva.nl/about/cere/cere.html?1583495894040, 2020. (Accessed 6 March 2020).

[52] E. Rodriguez-Lizundia, S. Marcos, E. Zalama, J. Gómez-García-Bermejo, A. Gordaliza, A bellboy robot: study of the effects of robot behavior on user engagement and comfort, Int. J. Hum. Comput. Stud. 82 (82) (2015) 83-95, https://doi.org/10.1016/j.ijhcs.2015.06.001.

[53] J. Nakanishi, I. Kuramoto, J. Baba, K. Ogawa, Y. Yoshikawa, H. Ishiguro, Continuous hospitality with social robots at a hotel, SN Applied Sciences 2 (3) (2020) 1-13.

[54] H. Osawa, A. Ema, H. Hattori, N. Akiya, N. Kanzaki, A. Kubo, T. Koyama, R. Ichise, Analysis of robot hotel: reconstruction of works with robots, in: International Symposium on Robot and Human Interactive Communication 219-223 IEEE, 2017.

[55] Henn-na hotel website, Hotel Facilities and detailed description. https://www. hennnahotel.com/en/facility/, 2020. (Accessed 6 March 2020).

[56] Y. Mou, C. Shi, T. Shen, K. Xu, A systematic review of the personality of robot: mapping its conceptualization, operationalization, contextualization and effects, Int. J. Hum. Comput. Interact. (2019) 1-15, https://doi.org/10.1080/ 10447318.2019.1663008.

[57] P.J. Hinds, T.L. Roberts, H. Jones, Whose job is it anyway? A study of humanrobot interaction in a collaborative task, Hum. Comput. Interact. 19 (1) (2004) $151-181$.

[58] D. Li, P.P. Rau, Y. Li, A cross-cultural study: effect of robot appearance and task, International Journal of Social Robotics 2 (2) (2010) 175-186.

[59] M. Touré-Tillery, A. McGill, Who or what to believe: trust and the differential persuasiveness of human and anthropomorphized messengers, J. Market. 79 (4) (2015) 94-110.

[60] C.E. Yu, Humanlike robots as employees in the hotel industry: thematic content analysis of online reviews, J. Hospit. Market. Manag. 29 (1) (2020) 22-38.

[61] Uniq Hotels, Henn-na hotel - Japanese robot hotel. https://www.uniqhotels. com/henn-na-hotel, 2019. (Accessed 29 February 2020).

[62] I. Tussyadiah, A review of research into automation in tourism: launching the annals of tourism research curated collection on artificial intelligence and robotics in tourism, Ann. Tourism Res. 81 (2020) 102883, https://doi.org/ 10.1016/j.annals.2020.102883.

[63] M. Jarrahi, Artificial intelligence and the future of work: human-AI symbiosis in organizational decision making, Bus. Horiz. 61 (4) (2018) 577-586.

[64] J. Reis, P.E. Santo, N. Melão, Impacts of artificial intelligence on public administration: a systematic literature review, in: 14th Iberian Conference on Information Systems and Technologies (CISTI) IEEE, 2019.

[65] N. Savage, Thinking deeply to make better speech 15-17. https://doi.org/10.114 5/3037384, 2017.

[66] S. Choi, S.Q. Liu, A.S. Mattila, How may I help you? Says a robot: examining language styles in the service encounter, Int. J. Hospit. Manag. 82 (2019) 32-38.

[67] Amazon, Amazon echo - black (1st generation. https://www.amazon.com/Amaz on-Echo-Bluetooth-Speaker-with-Alexa-Black/dp/B00X4WHP5E?th=1, 2020. (Accessed 2 March 2020)

[68] M. Langen, S. Heinrich, Humanoid robots: use cases as AI-lab companion: can an empathic and collaborative digital companion motivate innovation?, in: 2019 IEEE International Conference on Engineering, Technology and Innovation, 2019, https://doi.org/10.1109/ICE.2019.8792614.
[69] R. Tavakoli, P. Mura, Netnography in tourism-beyond web 2.0, Ann. Tourism Res. 73 (C) (2018) 190-192.

[70] M. Holt, Artificial Intelligence in Modern Society, vol. 138, Murray State University, 2018. Integrated Studies, https://digitalcommons.murraystate. edu/bis437/138.

[71] R. High, The Era of Cognitive Systems: an inside Look at IBM Watson and How it Works, IMB Corporation, Armonk, North Castle, NY, 2012.

[72] A. Gliozzo, C. Ackerson, R. Bhattacharya, A. Goering, A. Jumba, S.Y. Kim, L. Krishnmurthy, T. Lam, A. Littera, I. McIntosh, S. Murthy, M. Ribas, Building cognitive applications with IBM Watson services: vol 1 getting started, in: IBM Redbooks, 2017. http://www.redbooks.ibm.com/redbooks/pdfs/sg248387.pdf. (Accessed 1 March 2020).

[73] R. Pinillos, S. Marcos, R. Feliz, E. Zalama, J. Gómez-García-Bermejo, Long-term assessment of a service robot in a hotel environment, Robot. Autonom. Syst. 79 (2016) 40-57, https://doi.org/10.1016/j.robot.2016.01.014.

[74] Y. Gao, Z. Pan, H. Wang, G. Chen, Alexa, my love: analyzing reviews of amazon echo, in: 2018 IEEE SmartWorld, Ubiquitous Intelligence \& Computing, Advanced \& Trusted Computing, Scalable Computing \& Communications, Cloud \& Big Data Computing, Internet of People and Smart City Innovation, 2018, https://doi.org/10.1109/SmartWorld.2018.00094.

[75] C. Prentice, D. Lopes, X. Wang, The impact of artificial intelligence and employee service quality on customer satisfaction and loyalty, J. Hospit. Market. Manag. (2020), https://doi.org/10.1080/19368623.2020.1722304.

[76] L.N. Michaud, Observations of a new chatbot: drawing conclusions from early interactions with users, IT Professionals 20 (5) (2018) 40-47.

[77] C. Dirican, The impacts of robotics, artificial intelligence on business and economics, Procedia-Social and Behavioral Sciences 195 (2015) 564-573.

[78] M. Petticrew, H. Roberts, Systematic Reviews in the Social Sciences: A Practical Guide, John Wiley \& Sons, 2008.

[79] J. Jesson, L. Matheson, F.M. Lacey, Doing Your Literature Review: Traditional and Systematic Techniques, Sage, 2011.

[80] D. Tranfield, D. Denyer, P. Smart, Towards a methodology for developing evidence-informed management knowledge by means of systematic review, Br. J. Manag. 14 (3) (2003) 207-222.

[81] J. Reis, M. Amorim, N. Melão, P. Matos, Digital transformation: a literature review and guidelines for future research, WorldCIST'18 745 (2018) 411-421, https://doi.org/10.1007/978-3-319-77703-0 41.

[82] A. Bryman, B. Burgess, Analyzing Qualitative Data, Routledge, London, 2002.

[83] M. Bengtsson, How to plan and perform a qualitative study using content analysis, NursingPlus Open 2 (2016) 8-14.

[84] J. Reis, M. Amorim, N. Melão, Omni-channel service architectures in a technology-based business network: an empirical insight, in: International Conference on Exploring Service Science, vol. 331, Springer, Cham, 2018, pp. 31-44, https://doi.org/10.1007/978-3-030-00713-3_3.

[85] P. Bazeley, K. Jackson, Qualitative Data Analysis with NVivo, SAGE publications limited, London, 2013.

[86] A.J. Mills, G. Durepos, E. Wiebe (Eds.), Encyclopedia of Case Study Research, Sage Publications, California, 2009.

[87] J.W. Drisko, T. Maschi, Content analysis, in: Pocket Guides to Social Work Research Methods, Oxford, 2015.

[88] L.C. Leonidou, C.S. Katsikeas, D.N. Coudounaris, Five decades of business research into exporting: a bibliographic analysis, J. Int. Manag. 16 (1) (2010) 78-91.

[89] M.M. Keupp, M. Palmié, O. Gassmann, The strategic management of innovation: a systematic review and paths for future research, International journal of management reviews14 (4) (2012) 367-390.

[90] A.P. Chan, V.W. Tung, Examining the effects of robotic service on brand experience: the moderating role of hotel segment, J. Trav. Tourism Market. 36 (4) (2019) 458-468.

[91] S. Ivanov, C. Webster, A. Garenko, Young Russian adults' attitudes towards the potential use of robots in hotels, Technol. Soc. 55 (2018) 24-32.

[92] J. Nakanishi, I. Kuramoto, J. Baba, O. Kohei, Y. Yoshikawa, H. Ishiguro, Can a humanoid robot engage in heartwarming interaction service at a hotel?, in: Proceedings of the 6th International Conference on Human-Agent Interaction, 2018, https://doi.org/10.1145/3284432.3284448.

[93] S. Ivanov, U. Gretzel, K. Berezina, M. Sigala, C. Webster, Progress on robotics in hospitality and tourism: a review of the literature, Journal of Hospitality and Tourism Technology 10 (4) (2019) 489-521.

[94] M. Rajesh, Inside Japan's first robot-staffed hotel, Guardian (2015). https://www.theguardian.com/travel/2015/aug/14/japan-henn-na-h otel-staffed-by-robotsAccessed 19 Mar 2020.

[95] G. Wisskirchen, B. Biacabe, U. Bormann, A. Muntz, G. Niehaus, G. Soler, B. von Brauchitsch, Artificial Intelligence and Robotics and Their Impact on the Workplace, IBA Global Employment Institute, 2017.

[96] S. Shead, World's first robot hotel fires half of its robots. https://www.forbes. com/sites/samshead/2019/01/16/worlds-first-robot-hotel-fires-h alf-of-its-robots/\#fc2fe3ce1b1d, 2019. (Accessed 19 March 2020).

[97] V. Tung, N. Au, Exploring customer experiences with robotics in hospitality, Int. J. Contemp. Hospit. Manag. 30 (7) (2018) 2680-2697.

[98] T. Kikuchi, Robot staff make Japan's Henn na hotels quirky and efficient. http s://asia.nikkei.com/Business/Robot-staff-make-Japan-s-Henn-na-Hotels-q uirky-and-efficient, 2018. (Accessed 19 March 2020).

[99] Y. Zhang, X. Wang, X. Wu, W. Zhang, M. Jiang, M. Al-Khassaweneh, Intelligent hotel ROS-based service robot, in: 2019 IEEE International Conference on Electro Information Technology (EIT, IEEE, 2019, pp. 399-403. 
[100] R. Galin, R. Meshcheryakov, Human-robot interaction efficiency and humanrobot collaboration, in: Robotics: Industry 4.0 Issues \& New Intelligent Control Paradigms, Springer, Cham, 2020, pp. 55-63.

[101] J. Olszewska, M. Barreto, J. Bermejo-Alonso, J. Carbonera, A. Chibani, S. Fiorini, P. Goncalves, M. Habib, A. Khamis, A. Olivares, E. Freitas, E. Prestes, S. Ragavan, S. Redfield, R. Sanz, B. Spencer, H. Li, Ontology for autonomousrobotics, in: 2017 26th IEEE International Symposium on Robot and Human Interactive Communication (RO-MAN, IEEE, 2017, pp. 189-194.

[102] J. Calzado, A. Lindsay, C. Chen, G. Samuels, J. Olszewska, Sami: interactive, multi-sense robot architecture, in: 2018 IEEE 22nd International Conference on Intelligent Engineering Systems (INES, IEEE, 2018, pp. 317-322.

[103] N. Savela, T. Turja, A. Oksanen, Social acceptance of robots in different occupational fields: a systematic literature review, International Journal of Social Robotics 10 (4) (2018) 493-502.

[104] S. Ivanov, C. Webster, P. Seyyedi, Consumers' attitudes towards the introduction of robots in accommodation establishments, Turizam: međunarodniznanstvenostručničasopis 66 (3) (2018) 302-317.

[105] J. Pezzullo, G. Tung, J. Rogg, L. Davis, J. Brody, W. Mayo-Smith, Voice recognition dictation: radiologist as transcriptionist, J. Digit. Imag. 21 (4) (2008) 384-389.

[106] L. Metcalf, A. Askay, L. Rosenberg, Keeping humans in the loop: pooling knowledge through artificial swarm intelligence to improve business decision making, Calif. Manag. Rev. 61 (4) (2019) 84-109.

[107] McKinsey Global Institute, Artificial Intelligence: the next digital frontier?, 2017. Report Accessed 19 Mar 2020, http://bit.ly/2E3jReB. (Accessed 19 March 2020).

[108] D. Gartner, R. Kolisch, D. Neill, R. Padman, Machine learning approaches for early DRG classification and resource allocation, Inf. J. Comput. 27 (4) (2015) 718-734.

[109] J. Reis, M. Amorim, N. Melão, Multichannel service failure and recovery in a $\mathrm{O} 2 \mathrm{O}$ era: a qualitative multi-method research in the banking services industry, Int. J. Prod. Econ. 215 (2019) 24-33.

[110] H. Osawa, A. Ema, H. Hattori, N. Akiya, N. Kanzaki, A. Kubo, T. Koyama, $\mathrm{R}$. Ichise, What is real risk and benefit on work with robots? From the analysis of a robot hotel, in: Proceedings of the Companion of the 2017 ACM/IEEE International Conference on Human-Robot Interaction, ACM, 2017, pp. 241-242.

[111] Gulliver Travels, Why the World's First Robot Hotel Was a Disaster, The economist, 2019. https://www.economist.com/gulliver/2019/03/27/why-the -worlds-first-robot-hotel-was-a-disasterAccessed. (Accessed 26 April 2019).
[112] A. Hochschild, The Managed Heart: Commercialization of Human Feeling, University of California Press, 2012

[113] M. Čaić, G. Odekerken-Schröder, D. Mahr, Service robots: value co-creation and co-destruction in elderly care networks, Journal of Service Management 29 (2) (2018) 178-205.

[114] L. Pineda, A. Rodríguez, G. Fuentes, N. Hernández, M. Reyes, C. Rascón, R. Cruz, I. Vélez, H. Ortega, Opportunistic inference and emotion in service robots, J. Intell. Fuzzy Syst. 34 (5) (2018) 3301-3311.

[115] P. Liu, D. Glas, T. Kanda, H. Ishiguro, Learning proactive behavior for interactive social robots, Aut. Robots 42 (5) (2018) 1067-1085.

[116] X. Liu, K. Khan, Q. Farooq, Y. Hao, M. Arshad, Obstacle avoidance through gesture recognition: business advancement potential in robot navigation sociotechnology, Robotica 37 (10) (2019) 1663-1676.

[117] A. Qureshi, Y. Nakamura, Y. Yoshikawa, H. Ishiguro, Robot gains social intelligence through multimodal deep reinforcement learning, in: 2016 IEEE-RAS 16th International Conference on Humanoid Robots (Humanoids, IEEE, 2016, pp. 745-751.

[118] A. Ruiz-Garcia, N. Webb, V. Palade, M. Eastwood, M. Elshaw, Deep learning for real time facial expression recognition in social robots, in: International Conference on Neural Information Processing, Springer, Cham, 2018, pp. 392-402.

[119] J. Olszewska, M. Houghtaling, P. Goncalves, N. Fabiano, T. Haidegger, J. Carbonera, W. Patterson, S. Ragavan, S. Fiorini, E. Prestes, Robotic standard development life cycle in action, J. Intell. Rob. Syst. 98 (1) (2020) 119-131.

[120] T. Baum, Human Resource Management for Tourism, Hospitality and Leisure: an International Perspective, Thomson, London, 2006.

[121] G. Marchant, B. Allenby, R. Arkin, E. Barrett, J. Borenstein, L. Gaudet, O. Kittrie, P. Lin, G. Lucas, R. O'Meara, J. Silberman, International Governance of Autonomous Military robots. Handbook of Unmanned Aerial Vehicles, 2015, pp. 2879-2910.

[122] R. Herrero, J. Fentanes, M. Hanheide, Getting to know your robot customers: automated analysis of user identity and demographics for robots in the wild, IEEE Robotics and Automation Letters 3 (4) (2018) 3733-3740.

[123] S. Gössling, Tourism, information technologies and sustainability: an exploratory review, J. Sustain. Tourism 25 (7) (2017) 1024-1041.

[124] S. Shafiee, A. Ghatari, A. Hasanzadeh, S. Jahanyan, Developing a model for sustainable smart tourism destinations: a systematic review, Tourism Management Perspectives 31 (2019) 287-300. 